\title{
Pharyngeal Cyst
}

National Cancer Institute

\section{Source}

National Cancer Institute. Pharyngeal Cyst. NCI Thesaurus. Code C3934.

A cervical cyst that occurs as a result of the persistence of one or more of the pharyngeal grooves. 